1 Simpson JR. Functional MRI lie detection: too good to be true? J Am Acad Psychiatry Law 2008; 36: 491-8.

2 Bles M, Haynes JD. Detecting concealed information using brain-imaging technology. Neurocase 2008; 14: 82-92.

3 Sip KE, Roepstorff A, McGregor W, Frith CD. Detecting deception: the scope and limits. Trends Cogn Sci 2008; 12: 48-53.

4 Spence SA. Playing Devil's advocate: the case against fMRI lie detection. Legal and Criminological Psychology 2008; 13: 11-25.

5 Spence SA, Farrow TD, Herford AE, Wilkinson ID, Zheng Y Woodruff PWR. Behavioural and functional anatomical correlates of deception in humans. Neuroreport 2001; 12: 2849-53.

Rachael S. Fullam, Centre for Forensic Behavioural Science, School of Psychology, Psychiatry and Psychological Medicine, Monash University, Victorian Institute of Forensic Mental Health, Locked Bag 10, Fairfield VIC 3078, Australia. Email: rachael.fullam@forensicare.vic.gov.au; Mairead C. Dolan, Centre for Forensic Behavioural Science, Monash University, Australia

doi: 10.1192/bjp.195.3.270a

\section{Lithium in drinking water and food, and risk of suicide}

Ohgami et al ${ }^{1}$ reported lithium in drinking water $(0.7-59 \mathrm{gm} / \mathrm{l})$ and linked it to suicide rates. However, dietary lithium, which has received scant attention, is found in grains and vegetables, and to some extent animal-derived foods. ${ }^{2}$ Hence, considering only lithium in drinking water may not be enough of a link to suicide rates. Dietary sources of lithium may actually have made the difference rather than just the drinking water. Differences in the prevalence of mood disorders with natural lithium levels acting as a prophylactic have been reported., Jathar et $a l^{3}$ assessed the lithium content of the daily diet $(72.55-154.6 \mu \mathrm{g})$ and biological fluids, and hypothesised lithium to be a natural prophylactic. It will be interesting to see whether dietary and drinking water lithium levels have a direct impact on mood disorder prevalence, which in turn could explain the variation in suicide rates. And what about lithium-containing food cooked in lithium-containing tap water?

1 Ohgami $\mathrm{H}$, Terao $\mathrm{T}$, Shiotsuki I, Ishii $\mathrm{N}$, Iwata N. Lithium levels in drinking water and risk of suicide. Br J Psychiatry 2009; 194: 464-5.

2 Schrauzer GN. Lithium: occurrence, dietary intakes, nutritional essentiality. J Am Coll Nutr 2002; 21: 14-21.

3 Jathar VS, Pendharkar PR, Pandey VK, Raut SJ, Doongaji DR, Bharucha MP, et al. Manic depressive psychosis in India and the possible role of lithium as a natural prophylactic. II - Lithium content of diet and some biological fluids in Indian subjects. J Postgrad Med 1980; 26: 39-44.

4 Doongaji DR, Jathar VS, Satoskar RS. Manic depressive psychosis in India and the possible role of lithium as a natural prophylactic. I - Hypothesis. J Postgrad Med 1980; 26: 34-8.

Geetha Desai, Department of Psychiatry, National Institute of Mental Helath and Neurosciences, Bangalore 560029, India. Email: desaigeetha@gmail.com; Santosh K. Chaturvedi, Department of Psychiatry, National Institute of Mental Helath and Neurosciences, Bangalore, India

doi: 10.1192/bjp.195.3.271

The study by Ohgami et al ${ }^{1}$ raises serious ethical issues related to the interpretation of research findings and, as a consequence, their possible application. While not denying that the findings are interesting and have caused a stir in the lay press and on the internet, we question the methodology and the possible implications if the results are taken seriously.

First, sociological reasons for suicide are important, and changing rates of suicide in many countries are linked to changes such as migration, poverty, relationships and economic issues. The finding that when gender was included in the analysis there was a difference in the significance levels between men and women (with the results being less significant in women) is one such example. Adding lithium to tap water is not going to change these demographic and social factors that contribute to suicide rates, and not having accounted for at least some of these is a major limitation of the study. Second, although we agree with Young ${ }^{2}$ in his commentary that more research is needed to prove or disprove this tantalising idea, it is also important to assess what the impact of different levels of tap-water lithium is going to be on thyroid function, pregnant women and on the unborn fetus. It is also important to assess whether tap-water levels of lithium directly correlate with serum lithium levels in the respective populations. The levels of lithium in body fluids in normal healthy controls have varied from 0.01 to $0.09 \mathrm{meq} / 1$ in one study, ${ }^{3}$ but there are no data about serum lithium levels among individuals attempting suicide. Maybe assessment of serum lithium levels among those with suicidal behaviour can be a place to start. More data are also needed on the role of low-dose lithium in individuals without mood disorders who are at risk of suicide.

Finally, several foods (particularly spices) are known to have relatively high levels of lithium as reported by a study in India several years ago. ${ }^{3}$ This study reported levels as high as $12 \mu \mathrm{g} / \mathrm{g}$ of lithium in tobacco and high levels in crude salt, rock salt and several spices. Maybe, until such time that we are certain about lithium's role in decreasing suicidality in non-psychiatric populations, it might be worth conducting randomised controlled trials with these foods in individuals with suicidal behaviour to see whether low doses of lithium really help.

Let us not throw the lithium out with the tap water yet!

1 Ohgami H, Terao T, Shiotsuki I, Ishii N, Iwata N. Lithium levels in drinking water and risk of suicide. Br J Psychiatry 2009; 194: 464-5.

2 Young $\mathrm{AH}$. Invited commentary on ... Lithium levels in drinking water and risk of suicide. Br J Psychiatry 2009; 194: 466.

3 Jathar VS, Pendharkar PR, Pandey VK, Raut SJ, Doongaji DR, Bharucha MP, et al. Manic depressive psychosis in India and the possible role of lithium as a natural prophylactic. II - Lithium content of diet and some biological fluids in Indian subjects. J Postgrad Med 1980; 26: 39-44.

Prabha S. Chandra, Department of Psychiatry, National Institute of Mental Health and Neurosciences, Bangalore 560029, India. Email: prabhasch@gmail.com; Girish N. Babu, Department of Psychiatry, National Institute of Mental Health and Neurosciences, Bangalore, India

doi: 10.1192/bjp.195.3.271a

Authors' reply: We thank Drs Chandra and Babu for their comments, but we would like to emphasise that we had never recommended the addition of lithium to drinking water supplies ${ }^{1}$ because our findings are preliminary and yet to be conclusive.

First, we agree that sociological factors such as migration, poverty, human relations and economic issues may be associated with suicide rates, and have already admitted such limitations by stating 'other factors such as psychosocial and economic factors were not taken into consideration. ${ }^{1}$ Second, Drs Chandra and Babu state that it is also important to assess side-effects of lithium in tap water on thyroid function, pregnant women and the unborn fetus. Although it seems probable that these low levels of lithium are far below the levels required to produce side-effects, we agree with them. Third, they mention lithium levels in food, also raised by Drs Desai and Chaturvedi. This may be important because dietary lithium intake is estimated not to be a negligible quantity. For example, mean (s.d.) dietary lithium was reported to be: $1560 \mu \mathrm{g} /$ day (980) in China; 1485 (1009) (Tijuana) and 939 (928) (Culiacan) in Mexico; 1090 (324) in Sweden; 1009 (324) in Denmark; 821 (684) (Texas), 650 (740) (New York) and 429 (116) (San Diego) in the USA; 812 (383) in Japan; 406 (383) in Germany; and 348 (290) in Austria. ${ }^{2}$ Therefore, at the next stage, 